\title{
Awareness that coal-powered energy is environmentally degrading insignificantly affects its consumption
}

\author{
Angela T. Ragusa* \\ School of Humanities and Social Sciences, Charles Sturt U niversity, A lbury, NSW, A ustralia
}

\begin{abstract}
This paper contributes findings from a social survey conducted to examine individual awareness of coal's non-renewability, environmental issues, and home energy behaviours. The sample exhibited high (86\%) awareness of coal's non-renewability and 74\% self-identified energy issues as key environmental problems affecting their lives. Government presumptions that education campaigns are needed to increase A ustralian public awareness of carbon emissions and may induce pro-environmental energy behaviours are questioned. Energy issue awareness failed to significantly affect 4 home energy behaviours (choosing $\mathrm{A} / \mathrm{C}$ settings, type of home temperature control, turning lights off in unoccupied rooms, turning appliances off standby) for 'environmental sustainability' reasons. Findings support international research documenting disparity between individual awareness of environmental issues and pro-environmental actions for such issues. Consistent with prior research, age was the most significant factor affecting pro-environmental energy behaviours. Older individuals were most likely to consider environmental sustainability for home temperature and $\mathrm{A} / \mathrm{C}$ settings. Education, age, and energy issue awareness did not significantly affect 'low stakes' consumption behaviours (appliances or lights) for environmental reasons. In locations with nonrenewable energy, policy and education initiatives improving knowledge that aggregated carbon consumption from seemingly minor individual behaviours may reduce environmental degradation may make ‘unnecessary' energy consumption less culturally normative or acceptable.
\end{abstract}

\section{Introduction}

This paper presents social survey findings about environmental sustainability knowledge and home energy usage decisions displayed by individuals at an A ustralian university. A growing body of international energy research shows household income, family composition, community type, and other demographics predict household energy consumption, with most using consumer economics frameworks to investigate appliance usage rates [1-8]. Although government energy policies broadly note the environmental benefit of reducing energy consumption, conceptual frameworks focus on socioeconomic investigations of energy consumption, with most exploring how the socialisation processes affects youth and other family members' modification of household energy practices [5, 7, 9]. A limited, albeit growing, international body of research argues younger generations contribute to their household's increased energy expenditure because of their high technology consumption (i.e., Internet, mobile devices) [9, 7]. Despite a dearth of A ustralian research in this area, the limited findings to date compliment this literature, evidencing that age affects energy consumption and articulating the need for further examination of how social norms may affect energy behaviours [5]. The present study commences this task. This article presents key findings from an A ustralian sample to investigate if environmental knowledge and awareness affects environmental behaviours regarding home energy usage. It further questions if the relevance of age found internationally for energy consumption rates also exist in the A ustralian sample. A ge cohort, sometimes referred to as one's 'Generation', is shaped by cultural and historical influences that appear highly relevant in affecting proenvironmental behaviours, as found in A merican [10] and European [9] research. Research examining individuals' age and science literacy, specifically awareness and knowledge of environmental issues, may offer greater insight into identifying what predicts, or affects, energy consumption behaviours. Such research presently is under-investigated and conceptualised globally.

If energy consumption behaviours routinely display age-patterned differences, then, once behaviours are identified, strategies for supporting or changing such behaviours may begin to be addressed at policy, legislative, and educational levels. First, however, it is necessary to establish what level of environmental awareness any population possesses. Once such foundational information is known, then campaigns or programs for targeting specific elements of science literacy may commence for concerted environmental issues. If, for instance, a population does not know that coal is a finite fossil fuel that degrades the environment, then the role this knowledge plays in affecting energy behaviour remains unknown. Likewise, if environmental

\footnotetext{
Corresponding author: aragusa@csu.edu.au
} 
issues are perceived unimportant by specific populations when evaluating coal-powered energy, then actions supported by policy or practices that use environmental rationales to reduce coal-energy consumption would be unsuitable. The present study investigates such knowledge-behaviour dynamics in response to science communication and environmental psychology theories.

In a Digital Age characterised by plentiful information, providing additional scientific 'facts' often is an inadequate tactic for motivating behavioural change, particularly if actions are performed for cultural or emotive reasons [11-13]. For example, if a population has a 'high' level of awareness that coal is a finite energy resource and knows that coal-powered electricity is environmentally degrading, and, despite having this high level of science literacy they still choose to be high consumers of coal-powered energy, then factors beyond 'scientific recommendations' are likely prompting energy usage decisions. Perhaps there are no alternatives, perhaps the population is the coal industry, or perhaps there is some alternative sociocultural explanation. Research that only investigates energy consumption rates will remain unable to explain why environmentallydamaging behaviour continues. Conversely, if little environmental, or science literacy, is found for a population, for instance if most individuals think coal is renewable or harmless, then critiques of deficit models may be misguided [14].

International research attempting to distil why individuals do or do not act pro-environmentally is vexed.

Some find personal convenience trumps environmental reasons for specific behaviours [15], while others find having pro-environmental attitudes is a better predictor of pro-environmental behaviours than environmental knowledge [16]. Deficit models argue the way to change behaviour is to provide more information, or education, assuming a population lacks awareness of key facts or details. Hence, such models typically advocate better science education. The inadequacy of knowledge deficit models for solving complex social problems is increasingly identified in the literature [1719]. A lthough most environmental issues are grounded in complex social problems, government environmental campaigns continue to use knowledge deficit approaches and presume public ignorance. Australian examples include the state of Victoria's creation of the 2006 public education awareness campaign titled 'Black Balloons'. This television campaign was adopted by the NSW state government in 2014 and re-titled, 'You have the power. Save energy'. It depicted 'black balloons' emanating from appliances, including air conditioners, to visualise carbon emissions released from coal-powered electricity consumption. A critical review of the Black Balloons awareness campaign cited Victoria's Energy and Resources M inister stating, "the public realised that using renewable energy was a way to help the environment", and noted the campaign was heralded "highly effective" by producers and mass media [20]. I mportantly, how ever, the critique notes renewable energy supplied only $4 \%$ of the state's energy and, therefore, clean energy depends less on public awareness than availability of renewables the public can utilise [20].
Wide divergence persists between clean energy knowledge and behaviour. Theory in the social construction of knowledge suggests the relevance of science literacy lies in its social contextualisation [21]. Government expenditure on advertising campaigns to increase public education about carbon emission awareness is an unsuitable mechanism for solving environmental problems if it commences with the stereotype of public illiteracy or, if education alone, is insufficient to enable 'greener' choices to be adopted. Further, there is insufficient evidence that heightened awareness of environmental issues will sufficiently motivate individuals to terminate undesirable environmental behaviour. In A ustralia, public awareness of carbon emissions likely exists. This is visible, in part, by a plethora of 'green' products, such as reusable coffee cups, carbon calculators and offsetting schemes, and a host of 'greenwashing' advertising driving consumer spending in the new Millennium. Further, media coverage of Australia's agreement to the Kyoto Protocol, signed in 1998 and ratified in 2007 [22], predates governmental public education campaigns about carbon emissions. Hence, evidencing a population's need for science education, and ensuring that greater education will reduce the problem, before environmental education campaigns are commenced help fund activities best able to achieve the changes desired.

Regardless of energy issue awareness, economic incentives are necessary to drive renewable energy consumption in Australia because banks will not finance new coal-fired generators. Renewable energy consumption is supported by industry- and consumer-led innovations such as reduced solar/wind power cost and heightened cost of 'traditional' electricity due to gas price increases [23]. Political analysts argue ideological debates inhibit the Australian Government's reduction of greenhouse gas emissions since it is the Australian Government that directly funds the nation's coal-fired electricity dependency [23]. The disparate political agendas and spending priorities among government agencies and branches illustrates need to expand focus beyond consumer education and private adoption of 'green' electricity to include auctioning federal responsibility for the environmental degradation caused by the Australian Government funding non-renewables.

Cross-national comparisons reveal Australia's coal power plants exceed toxic air pollution levels permissible in A merica, China, and Europe; coal plants in the state of New South Wales (NSW) emit mercury levels 666x A merican limits [24]. A ustralia has no national standards for particulate pollution and its questionable coal-plant emissions reporting practices are documented and continue [24]. The W orld Health Organization notes coalfired power plants are a major source of air pollution and $11.6 \%$ of deaths globally are due to air pollution [25]. The human and environmental health implications of governance structures and individual behaviours perpetuating coal-powered energy consumption, therefore, make knowledge about coal, and coal-dependent energy consumption, a research focus with applied, as well as academic, urgency. Practically, this study may interest those working towards meeting Australian Government 
target activities and commitments to national reductions in greenhouse gas emissions as part of global strategies pursued in conjunction with the United Nations Framew ork Convention on Climate Change. In A ustralia, targets show reductions in the electricity sector are offsetting increased emissions from diesel consumption by industry, specifically mining and transportation, liquefied natural gas exportation, and metal [26]. NSW is A ustralia's most populous state [27] and continues to have $80 \%$ of its electricity fuelled by coal-powered plants that account for $48 \%$ of the country's greenhouse gas emissions when coal mining for the electricity production is included in greenhouse gas emission calculations [28]. Future Government spending to enhance public education about carbon emissions thus may be better utilised if diverted to fund initiatives supporting renewable energy production. In particular, if research finds high general awareness al ready exists about coal's finite capacity for energy generation and its contribution to carbon emissions, then policy and alternative energy are needed more than public education.

Politically, if popular support for renewable energy is a prerequisite for transitioning from coal to clean energy, then the present research offers a method and case example for identifying individual perceptions and actions using social research methods. Documenting specific behaviours individuals do, and do not do, to reduce their energy consumption for 'environmental' reasons, alongside awareness of key energy issues, may help identify if or what need exists for public education verses legislative change. In undertaking such research, this study shifts the limited A ustralian research focusing on how family socialisation norms affect domestic energy consumption [5] towards questioning energy governance.

Finally, it is necessary to note cultural and economic factors affecting energy decisions may also be mediated by physical environments. In the research location, where extremely hot $(>40 \mathrm{C})$ summers encourage use of electricity-based air conditioning $(\mathrm{A} / \mathrm{C})$, personal physical discomfort may outweigh other factors affecting home energy use decisions. Likewise, if personal convenience is prioritised, as international research found [15], then pro-environmental energy behaviours with minimal economic savings that also are inconvenient, such as turning off lights in unoccupied rooms or turning off appliances at the power source to avoid 'standby' electricity consumption, are unlikely to be undertaken without strong sociocultural sanctions. This paper contributes to the discrepant and multi-disciplinary literature by presenting findings from exploratory research undertaken at an Australian university. Findings are not representative of the Australian public at large. Rather, they provide exploratory data addressing 6 research questions that future researchers may wish to use in collecting further exploratory or nationallyrepresentative samples:

i. Do most respondents know coal is a non-renewable energy source?

ii. Is there a relationship between individual awareness of coal's non-renewability and home energy behaviours reported (choosing $A / C$ settings, type of home temperature control, turning lights off in unoccupied rooms, turning appliances off standby)?

iii. Is there a relationship between age or education and home energy behaviours?

iv. Does convenience or physical comfort affect what energy consumption behaviours are undertaken?

v. How prominent is 'energy' as a self-identified issue reported in the 'top 3 environmental sustainability issues affecting respondents' lives'?

vi. Is energy, as an environmental sustainability issue, associated with pro-environmental energy behaviours?

\section{Methods}

Human research ethics approval was sought and obtained prior to the research commencing. The research was supported by a small grant received from the university division responsible for promoting environmental sustainability. No conflict of interest or adverse consequences arose during this study. Respondents gave their informed consent to voluntarily participate and received no remuneration other than entry into a raffle for iTunes gift certificates or an iPad which the small grant supported. The online survey was hosted on the university's server. Accessing the survey required respondents to enter their unique identification password. Survey recruitment consisted of announcements being made on the member-only section of the university's website. The recruitment strategy was chosen because the research population is geographically disbursed over hundreds of kilometres in A ustralia [29]. This strategy yielded a non-probability sample and gave all members in the population the possibility of participating. Findings are not representative of the broader A ustralian public.

The survey contained open- and close-ended questions. This permitted collection of demographic and environmental sustainability knowledge and behaviour data. Qualitative and quantitative data were entered into SPSS. This paper presents findings related to energy issue awareness and behaviour. To assess respondents' environmental science literacy, respondents were asked, to if coal was a renewable energy source. To obtain data about individuals' environmental behaviours related to energy, 4 questions were asked. Three questions asked how often (in the past 6 months) they considered environmental impacts when they a) selected $A / C$ settings b) turned off lights in unoccupied rooms or c) turned off appliances at the wall (i.e., turned them off standby). Answer options were 'never', 'once', '2-5 times', 'most times', or 'always'. The fourth energy behaviour question asked if environmental sustainability concerns affected their decisions about choosing the type of temperature control in their home. Answer categories were 'major consideration', 'minor consideration', or 'not considered/applicable'. 'Temperature Control' was recoded into a dummy variable (coded $1=y e s$, affected decision, and 2=no, didn't affect decision). This was cross-tabulated with 'Year of Birth' which was recoded into Generations (Baby Boomer, Generation $X$, and Millennials). 'Traditionalists' were removed due to their low frequency $(n=5)$ in the sample. Descriptive statistics, 
Pearson Correlations (2-tailed), Chi Square, and Regression analyses were run to explore relationships between age and home energy behaviours. Finally, content analysis [30] was conducted for answers provided to the open-ended question, what do you consider to be the top three environmental sustainability issues affecting your life? Content analysis permitted identification of the quantity and type of energy issues respondents' qualitatively listed. The variable 'Energy Top Issue' was created ( $1=y e s, 2=n o)$, with 'yes' indicating those listing energy issues in their 'top 3' environmental sustainability issues. Finally, statistics were run to explore if individual energy issue awareness affected energy behaviours or knowledge of coal's (non)renew ability.

\section{Results \& Discussion}

A total of 412 useable surveys were completed. Sample demographics found fewer men (32\%) completed the survey than women. The mean age was 42 (minimum 18, maximum 79). Baby B oomer (30\%), Generation X (32\%), and Generation Y/Millennial (36\%) birth cohorts were relatively evenly represented. Few (1\%) Traditionalists participated. M ost (90\%) respondents were Australianborn, with $94 \%$ raised in eastern A ustralia. Thirty-two percent were employed in continuing or casual academic positions and $46 \%$ held administrative roles. A minority (16\%) were studying or unemployed (retired). The majority (68\%) had at least a Bachelor's degree.

Irrespective of gender, age, education, or employment role at the university, most (86\%) knew coal was not a renewable energy source. Six percent 'didn't know' and very few (7\%) thought coal was renewable. A weak negative correlation emerged between respondents' knowledge of coal's non-renewability and turning lights off in empty rooms $(-.120, .01, N=411)$. No significant relationship existed between knowledge of coal's nonrenewability and considering the environment when choosing their type of home temperature control or A/C settings. Neither age, nor education, was associated with turning appliances off standby or turning lights off in empty rooms for environmental reasons (two 'low stakes' behaviours because of their small personal economic gain from electricity savings). A weak correlation showed women may be slightly more inclined to turn off appliances than men $(.108, .03, N=399)$.

In contrast, age and education were strongly associated with both temperature control and $A / C$ settings; the older respondents were, the more likely they were to consider the environment when selecting $A / C$ settings (.188, $.000, N=401)$ or temperature control for their home $(.170, .001, N=406)$. R espondents who considered the environment when controlling their home's temperature $\mathrm{C}^{2}(2, N=401)=11.45, p=.01$ and $\mathrm{A} / \mathrm{C}$ settings $C^{2}(8, N=396)=17.60, p=.05$ significantly differed by generation. Table 1 illustrates crosstabulations.
Table 1. Generation and environmental consideration of home temperature control and $A / C$ settings.

\begin{tabular}{|c|c|c|c|c|c|c|c|}
\hline & \multicolumn{3}{|c|}{$\begin{array}{c}\text { Temperature } \\
\text { control }\end{array}$} & \multicolumn{4}{c|}{ A/C settings } \\
\hline & No & Y es & $\Sigma$ & $0-1$ & $\begin{array}{c}2- \\
5 x\end{array}$ & $\begin{array}{c}\text { M ost / } \\
\text { Every }\end{array}$ & $\Sigma$ \\
\hline GenY & 66 & 83 & 149 & 48 & 27 & 71 & 146 \\
\hline GenX & 45 & 85 & 130 & 37 & 19 & 72 & 128 \\
\hline $\begin{array}{c}\text { Baby } \\
\text { B'mer }\end{array}$ & 30 & 92 & 122 & 26 & 15 & 81 & 122 \\
\hline$\Sigma$ & 141 & 260 & 401 & 111 & 61 & 224 & 396 \\
\hline
\end{tabular}

Higher education ( $>$ Bachelor's degree) was significantly associated with considering the environmental impact of choosing $A / C$ settings at home $(.182, .000, N=399)$ and weakly associated with choosing type of home temperature control $(.120, .016, N$ $=404)$. Multiple regression analysis found age and education explained $5.3 \%$ of the variance $\left(R^{2}=.05, F(1,2)\right.$ $=11.04, p<.01)$ for environmental consideration when selecting $A / C$ settings. Age significantly predicted consideration of environmental impact when selecting $\mathrm{A} / \mathrm{C}$ settings $(\beta=.02, \mathrm{p}<.01)$, better than having a higher education degree $(\beta=.42, p<.05)$. Multiple regression analysis found age and education explained $4.8 \%$ of the variance $\left(R^{2}=.05, F(1,399)=20.16, p<.01\right)$ for environmental consideration when selecting type of home temperature control, yet only age was independently significant in the model $(\beta=.01, \mathrm{p}<.01)$ since having a higher education degree was insignificant $(\beta=.07, \mathrm{p}<.15)$.

Qualitatively, although the majority $(74 \%)$ selfidentified an energy issue among the top 3 environmental sustainability issues affecting their lives, no statistically significant results were found between energy issue awareness and home energy behaviours. Likewise, no statistically significant demographic relationships emerged for environmental energy issue awareness. Table 2 illustrates the respondent-identified issues related to 'energy' by their designated ranking of importance. Insufficient renewable or sustainable energy alternatives to coal-powered energy was the most commonly (27\%) self-identified issue, albeit the negative impacts of 'climate change' were ranked 'most important' $(n=67 / 16 \%)$ more frequently than every other energy issue qualitatively described.

The findings begin addressing social research gaps exploring relationships among sociodemographic characteristics, particularly age, awareness, and behaviours influencing home energy consumption $[5,7]$ and supports fiscal energy analyses of residential electricity usage showing the relevance of age $[1-4,6]$. Specifically, it contributes an Australian sample to international studies noting older individuals are more likely to consider environmental impacts of energy consumption $[9,7]$. Results found older individuals were most likely to consider environmental sustainability when choosing their home temperature control options and A/C settings. Although age significantly predicted who considered the environment when making home temperature control and $A / C$ setting decisions, the small percent of variance explained by the regression models reproduces challenges many social science researchers 
face in attempting to explain complex human behaviours with few variables. Since A merican research controlling for income and education found generational norms are what statistically predict environmental conservation behaviours [10], need exists to further distil what specific aspects of age generation cohorts and/or higher education affect environmental decisions in A ustralia. Finally, the high level of awareness about coal's non-renewability, and that such knowledge did not significantly affect energy behaviours, questions the utility of providing more 'general' scientific information as a mechanism for social change. This supports international research documenting environmental issue awareness does not necessarily lead to pro-environmental actions around such issues, which also depends upon the activity's perceived level of inconvenience and economic incentives [1, 31-34].

Table 2. Respondent-generated 'top 3' environmental issues affecting their lives related to 'energy'.

\begin{tabular}{|c|c|c|c|c|}
\hline Energy Issue & $\begin{array}{c}\text { Most } \\
\text { important }\end{array}$ & $\begin{array}{l}\text { Second } \\
\text { issue }\end{array}$ & $\begin{array}{l}\text { Third } \\
\text { issue }\end{array}$ & Total \% \\
\hline $\begin{array}{c}\text { Renewable/sustainable } \\
\text { energy shortages }\end{array}$ & 45 & 41 & 25 & $27 \%$ \\
\hline $\begin{array}{l}\text { Climate change } \\
\text { impacts }\end{array}$ & 67 & 16 & 8 & $22 \%$ \\
\hline $\begin{array}{l}\text { Fossil fuel use / } \\
\text { depletion }\end{array}$ & 21 & 30 & 24 & $18 \%$ \\
\hline $\begin{array}{l}\text { Global warming } \\
\text { impacts }\end{array}$ & 26 & 9 & 7 & $10 \%$ \\
\hline $\begin{array}{l}\text { Carbon emissions } \\
\text { impacts }\end{array}$ & 17 & 11 & 7 & $8 \%$ \\
\hline $\begin{array}{l}\text { Greenhouse gas / } \\
\text { ozone hole }\end{array}$ & 8 & 8 & 5 & $5 \%$ \\
\hline Nuclear power impacts & 0 & 0 & 1 & $<1 \%$ \\
\hline B rown coal energy & 0 & 0 & 1 & $<1 \%$ \\
\hline
\end{tabular}

\section{Conclusions}

Collection of a nationally-representative sample that tests if the results found in the present sample illustrate national or international trends may commence documenting how widespread awareness of coal's nonrenewability and the connection between high coal energy consumption and negative environmental impacts. Documenting whether individuals believe energy issues personally affect their lives at national and global levels may facilitate better targeting of education campaigns. Posing location-specific questions, such as measuring individual awareness that $80 \%$ of NSW's electricity is derived from coal-powered plants [28] and assessing knowledge of linkages between air pollution and mortality rates [25], may test science literacy about environmental issues beyond 'generalist' knowledge. Further, for behaviours with perceived or real low environmental benefit, such as turning lights or appliances off standby, then targeted education that explains the cumulative effect of 'low stakes' individual actions may help change normative assumptions. Where scientific literacy is high and energy behaviours are performed for personal convenience reasons, regardless of environmental awareness [15], then policy or legislation may be required to change unpopular actions having high environmental consequences [35]. A cademic research is needed to engage with critical news reporting accounts, such as the over-estimation of the success of government campaigns, such as the 'Black Balloon' public education initiatives [20]. Further, identifying why specific pro-environmental actions are not taken would help efforts to incentivise specific behaviours, particularly those affecting government and industry emission target achievements [26, 28].

Age-specific sociocultural factors that predict environmental behaviours, beyond 'hard or soft' regulations and economic incentives [36], remain unknown. Factors contributing to the 'high cost' of electricity in Australia are well documented [23]. Nevertheless, 'simple' energy conservation behaviours, such as turning appliances off standby and lights off in empty rooms, were not undertaken for environmental reasons. These are two of many possibilities that future research could examine using nationally representative samples to test if 'deeper' environmental knowledge and/or social norms hold potential to change personal actions. Borrowing the concept 'tragedy of commons', created from British cultural observations, offers one opportunity to highlight although humanity may believe single actions have little environmental consequence, when each action is multiplied by population size, the consequences may be tragic. Conceptually, this may augment frameworks that bifurcate between 'carrot or stick' ideologies apparent in much socio-environmental research and policy [35].

This re-conceptualisation is particularly relevant where renewable energy is unavailable. Policy and educational initiatives that commence focusing on reducing 'unnecessary' energy consumption and requires minimal personal effort. This 'first step' recommendation for energy reduction would achieve key criteria prior research suggests necessary for cultivating proenvironmental actions. As voluntarily personal actions, 'low stakes' behaviours, such as turning lights off in empty rooms and appliances off standby, require little personal effort, sacrifice, or economic disadvantage. As 'low stakes' behaviours become socially normative, they would be regulated informally and thus it would bypass Western culture's distaste for 'strong' regulation, key factors international literature shows affect environmental action [36, 37, 33]. With 'deeper' learning, heighted normativity, and positive feedback about the beneficial human and environmental health implications such 'little' changes may have collectively for reducing 'unnecessary' energy expenditure, achievements may be used to expand foci to initiatives aimed at changing 'harder' behaviours, such as home temperature control. In so doing, targeted age cohort campaigns could ensure every age group equitably contributes to the health and well-being of themselves and their local/global environments. Concurrently, energy consumption behaviours targeting individuals may be complimented by global initiatives targeted at regulating nation-states. Collectively, 'macro' and 'micro' approaches may improve the socio-cultural normativity of global energy consumption and deepen knowledge of the aggregated negative effects coal- 
powered energy consumption poses to environmental and human health.

\section{References}

1. D. Brounen, N. Kok, J.M. Quigley, Eur. Econ. Rev. 56, 931 (2012)

2. W.H. Huang, Energy 87, 120 (2015)

3. A. Kavousian, R. Rajagopal, M. Fischer, Energy 55, 18 (2013)

4. M. J. Kim, Fam. Consumer. Sci. Res. J. 47, 42 (2018)

5. J. K leinschafer, M. M orrison, Int. J. Consum. Stud. 38, 75 (2014)

6. F. M CLoughlin, A. Duffy, M. Conlon, Energy Build 48, 240 (2012)

7. H. Wallis, M. Nachreiner, E. M atthies, Energ. Policy 94, 224 (2016)

8. P. W yatt, Energ. Policy 60, 540 (2013)

9. L. Schmidt, A. Horta, A. Correia, S. Fonseca, Nat. Cult. 9, 183 (2014)

10. L. Brown, D. Robertson, A cad. B ank. Stud. J. 10, 45 (2011)

11. B. Fischhoff, D.A. Scheufele, Proc. Natl. A cad. Sci. USA 111 Supp 4, 13583 (2014)

12. S. M isra, D. Stokols, Environ. Behav. 44, 737 (2012)

13. A.B. Unal, L. Steg, M. Gorsira, Environ. Behav. 50, 1092 (2018)

14. G. M eyer, Public Underst. Sci. 25, 433 (2016)

15. S. de Luca, R. di Pace, Transp. Res. D Transp. Environ. 71, 59 (2015)

16. R. A froz, M.M. M uhammad, A. Rulia, I. A shraful, J.B. Duasa, Environ. Sci. Pollut. Res. Int. 22, 16153 (2015)

17. K.M. Gallagher, J.A. U pdegraff, Ann. B ehav. Med. 43, 101 (2012)

18. D. K ahan, Polit. Psychol. 36, 1 (2015)

19. A.T. Ragusa, A. Crampton, A m. J. Health Educ. 50, 176 (2019)
20. D. Rood, The A ge. (2007 M arch 13)

21. B. L atour, Science in Action (1999)

22. Parliament of A ustralia, The Kyoto protocol (2019)

23. I. V errender, A ustr. B roadcast. Corp. (2018 J ul 16)

24. M. Slezak,. M ail Guard. (2017 A ug 15)

25. W orld Health Organisation. Country estimates on air pollution exposure and health impact. (2016)

26. Australian Government. Quarterly update of Australia's national greenhouse gas inventory for December 2018, (2019)

27. Population A ustralia. Australia population. (2019)

28. NSW Government Planning \& Environment. Future of NSW coal fired power generation, Coal Innovation NSW, (2019)

29. W .L. N euman, Basics of Social Research (2011)

30. E. Babbie, The Basics of Social Research (2001)

31. J. Gould, T.F. Golob, 1998 Transp. Res. D Transp. Environ. 3, 157 (1998)

32. K.S. Kurani, T. Turrentine, D. Sperling, 1996 Transp. Res. Part D: Transp. Environ. 1, 131 (1996)

33. O. M airesse, C. M acharis, K. Lebeau, L. Turcksin, Psicologica 33, 547 (2012)

34. D. Pojani, D. Stead, D Sustainability 7, 7784 (2015)

35. D. Banister, J. Pucher, M. Lee-Gosselin, 2007 $M$ aking sustainable transport politically and publicly acceptable Institutions and Sustainable Transport: Regulatory R eform in Advanced Economies (2007)

36. S. A ttari, M. Schoen, C. Davidson, M.L. Dekay, W.B. de Bruin, R.M. Dawes, M.J. Small, Ecol. Econ. 68, 1701 (2009)

37. S. Clayton, C. M anning, K. Krygsman, M. Speiser, Mental health and our changing climate.(2017) 